\title{
Los sujetos procesales en el Código Procesal Peruano de 2004 (acusatorio, garantizador, de tendencia adversativa, eficiente y eficaz)
}

\author{
MARIO PABLO RODRÍGUEZ HURTADO*
}

\begin{abstract}
SUMARIO: INTRODUCCIÓN.- I. JURISDICCIÓN, ATRIBUTO DE LOS JUECES.II. LA DIVISIÓN DE FUNCIONES PROCESALES COMO CARACTERÍSTICA RESALTANTE DEL CPP.- III. EL MINISTERIO PÚBLICO.- IV. EL IMPUTADO Y SU ABOGADO DEFENSOR.- V. VÍCTIMA Y ACTOR CIVIL.- VI. CONCLUSIÓN.VII. INTERROGANTES Y CASOS PRÁCTICOS.
\end{abstract}

\section{INTRODUCCIÓN}

Una característica central del modelo acusatorio es la rigurosa determinación que efectúa de las funciones procesales básicas y la asignación de ellas al correspondiente sujeto procesal. Siguiendo las pautas contenidas en sus artículos 159, 139.14 y 138, la Ley Suprema identifica las tareas centrales sin la cuales no podría siquiera hablarse de proceso penal. Estas son la de persecución del delito, que importa, a su vez, investigar, acusar (cuando corresponda) y probar la acusación para alcanzar un veredicto de culpabilidad y una condena; la de defensa o resistencia a la persecución, dirigida a desvirtuar las imputaciones que soporta el procesado, entendida tanto en sentido material, o derecho a ser escuchado, como técnica, o a ser patrocinado por un profesional del Derecho, de elección o de oficio; y la de enjuiciamiento o fallo para resolver el conflicto impartiendo justicia imparcial, sobre la base de la valoración de la actuación probatoria practicada en juicio por las partes en contienda. Este círculo de funciones se cierra con la atribución que se hace de ellas al sujeto procesal respectivo: la de persecución al Ministerio Público, la de defensa al propio imputado y su abogado patrocinador, y la de administración de justicia al órgano jurisdiccional.

El nuevo Código Procesal Penal de 2004 (en adelante CPP), al desarrollar las pautas constitucionales en este campo, hace igual reconocimiento de las funciones procesales básicas y la asignación específica de ellas. Por eso, su título preliminar distingue los alcances de la titularidad de la acción penal (II) ${ }^{1}$, el derecho de defensa (IX) y la competencia judicial $(\mathrm{V})$, a lo que debe agregarse el tratamiento que luego da al Ministerio Público (60), a su brazo operativo, la policía (67), al imputado (71), al abogado defensor (80) y al órgano jurisdiccional (16).

* Es abogado y profesor de la Pontificia Universidad Católica del Perú, de la Universidad Nacional Mayor de San Marcos y de la Academia de la Magistratura del Perú. Sus correos electrónicos son mprodrig@ pucp.edu.pe y maparo@amauta.rcp.net.pe.

1 La numeración, salvo otra indicación, está referida a los artículos del CPP. 
He aquí los actores principales, no los únicos, del drama procesal penal, ya que no hay que olvidar que el nuevo modelo también rescata y revitaliza a la víctima (94) y al actor civil (98), así como reconoce los derechos de las personas jurídicas, sujetos pasivos de la relación procesal, en la medida en que se les atribuya haber sido organizadas para delinquir, o empleadas con ese fin (90), del tercero civil (111), del querellante particular (107) y de aquellos que celebraron actos jurídicos con el imputado, luego de la comisión del delito, sobre su patrimonio y arguyen buena fe (15).

\section{JURISDICCIÓN, ATRIBUTO DE LOS JUECES}

Como la Constitución lo indica, la potestad de impartir justicia emana del pueblo y se ejerce mediante el Poder Judicial. La resolución de los conflictos generados por los delitos no puede efectuarse de cualquier manera: requiere que, en la cúspide de la estructura procesal, actúe un órgano investido de plenas prerrogativas que le permitan que todos, personas e instituciones, le deban obediencia y colaboración; que sus disposiciones tengan efectividad al estar respaldadas por el poder coercitivo; y que sus decisiones sean efectivamente ejecutadas. Así lo entiende el CPP cuando indica que la justicia penal se imparte con imparcialidad por los órganos jurisdiccionales competentes (I.1). La jurisdicción penal común es, entonces, la llamada a zanjar la pugna establecida entre las pretensiones procesales (punitiva del fiscal y libertaria del acusado) dentro del marco de un juicio previo, oral, público y contradictorio (I.2). Ambos asuntos van de la mano porque están relacionados tanto con el órgano que decide como con el escenario y actuaciones, las del juzgamiento, sobre cuya base se emite la sentencia (3931). La idea que descansa en todo esto es que el órgano jurisdiccional cumpla eficientemente su trabajo al hacerse cargo de un juicio en el cual se aseguren sus principios capitales (356)

\section{I.1. Potestad jurisdiccional}

El colectivo de órganos que ejercen la potestad jurisdiccional del Estado en materia penal está compuesto por la Sala Penal de la Corte Suprema, por las Salas Penales de las Cortes Superiores, por los Juzgados Penales, colegiados o unipersonales, por los Juzgados de la Investigación Preparatoria y por los Juzgados de Paz Letrados (16). Detenerse a considerar por qué se ha hecho esta distribución es instructivo, pues permite descubrir que el CPP, inteligentemente, ha querido preservar al máximo la imparcialidad judicial: de ahí que esencialmente diferencie entre los Juzgados de la Investigación Preparatoria, órganos de tutela y de garantías en esta fase, y de control y saneamiento en la etapa intermedia (29, 345 y 351), de los Juzgados Penales, dedicados, más bien, a dirigir el juicio público y a emitir sentencia. Así se evita, pues, que los órganos de juzgamiento se contaminen innecesariamente con intervenciones en 
actuaciones precedentes al juzgamiento. Con respecto a las Salas Penales Superiores, interesa saber que entre sus funciones más señaladas está la de conocer las apelaciones de autos y sentencias que emitan los Juzgados de la Investigación Preparatoria y los Juzgados Penales (271), y que para resolver impugnaciones de sentencias es admisible el ofrecimiento de pruebas en segunda instancia (422) y la necesaria realización de audiencias de apelación (424). En relación con la potestad de la Sala Penal de Corte Suprema, destaca el conocimiento del recurso de casación interpuesto contra las sentencias y autos expedidos en segunda instancia por las Salas Penales de las Cortes Superiores, en los casos previstos por la ley (26). Tratándose de un recurso extraordinario, las causas de procedencia son muy estrictas, esto es, tasadas, aunque discrecionalmente la Sala Penal Suprema puede concederlo cuando lo considere necesario para el desarrollo de la doctrina jurisprudencial (427).

Es correcto decir que la jurisdicción penal se extiende a los delitos y a las faltas, y que invoca como criterios de aplicación los establecidos en el Código Penal (CP) y en los tratados internacionales, aprobados y ratificados por el Perú, conforme con la Constitución $(17,482)$; de ahí que el CPP destine, por ejemplo, todo su Libro Séptimo (508-566), vigente a plenitud conforme con la ley $28671^{2}$, publicada el 31 de enero de 2006, a la Cooperación Judicial Internacional, incluida la sección referente a la Cooperación con la Corte Penal Internacional (554). La jurisdicción penal ordinaria encuentra su límite (18), en cambio, frente a los delitos de función militar o policial (173 de la Constitución), cuya esencia reside en la afectación de bienes jurídicos no comunes sino estrictamente castrenses; a las infracciones de la ley penal que cometen los adolescentes (183 del Código de los Niños y Adolescentes); y, he aquí algo muy interesante, aunque poco referido y menos estudiado, a los casos privativos de la función jurisdiccional por las comunidades y las rondas campesinas y nativas (149 de la Constitución) $)^{3}$.

\section{I.2. Competencia}

Entendida como la distribución de la jurisdicción entre los diferentes órganos que la detentan, presenta en el CPP criterios territoriales (21), en determinada medida afectados por la ocurrencia de delitos graves y de trascendencia nacional (24, modificado por decreto legislativo 983) que permiten su conocimiento por los jueces de la capital de la República, con prescindencia del lugar de perpetración; y razones objetivas y funcionales relacionadas con determinado tipo de personas (aforados), división de los hechos punibles en delitos y faltas, mayor o

2 La ley 29305 del 22 de diciembre de 2008 ha modificado los artículos 542 y 544, sobre las condiciones para el traslado y el cumplimiento de condenas de extranjeros.

3 Véase el acuerdo plenario 1-2009/CJ-116, fundamento artículo 116 TUO LOPJ, asunto Rondas Campesinas y Derecho Penal. En V Pleno Jurisdiccional de las Salas Penales Permanente y Transitorias. Separata «Jurisprudencia». El Peruano [Lima], año XIX, Nº 898, pp. 6551-6554. 
menor gravedad de los primeros y rol cumplido por los órganos judiciales durante las diversas etapas del proceso (26-30).

En esta área, importa anotar que el CPP ha efectuado una terminante diferenciación entre los órganos jurisdiccionales para asignarles a unos la condición de Juzgados de la Investigación Preparatoria y a otros la de Juzgados Penales, de enjuiciamiento y fallo.

\section{I.3. El juez de la investigación preparatoria o juez de garantías} Se trata de una figura novísima (29) que rompe el viejo esquema de la instrucción con dos órganos persecutores: por un lado, el fiscal, desplegando indagaciones preliminares hasta formalizar su denuncia; y, por el otro, el juez instructor o pesquisa a cargo de la llamada «investigación formal» una vez emitido el auto de apertura de instrucción. Esta rémora, propia de los procedimientos sumarios (decreto legislativo 124) y ordinarios (Código de Procedimientos Penales [C de PP] y ley 26689), ha sido cortada de raíz por el CPP, porque para él solo existe un órgano investigador, desde el inicio o noticia criminal, el Ministerio Público (IV.1). En tanto, el juez que participa en esta etapa de pesquisa no se inmiscuye en ella ni cumple la menor tarea de inquirir o indagar, sino que efectiviza su presencia para asegurar garantías y tutelar al justiciable (714), despachar medidas coercitivas o restrictivas de derechos fundamentales y efectuar el control y el saneamiento durante la etapa intermedia del proceso común (29), ello sin perjuicio de practicar, en casos extremos y a solicitud de las partes, prueba anticipada (242).

Claros ejemplos de estas importantes tareas del juez de la investigación preparatoria se encuentran en lo siguiente:

- audiencia de tutela, para subsanar omisiones o dictar medidas de corrección o protección, a solicitud del imputado cuando este considere que sus derechos no son respetados, que es objeto de medidas limitativas de derechos indebidas o requerimientos ilegales (714);

- expedición de medidas restrictivas de un derecho fundamental en razón de búsqueda de pruebas (2031), como lo son, entre otros, el allanamiento (214) y la intervención de comunicaciones telefónicas o análogas (230);

- emisión de medidas de coerción procesal o su cesación (254): por ejemplo, la prisión preventiva (268);

- audiencia de control del plazo de las diligencias preliminares de investigación (3342);

- procedencia de actos de investigación solicitados por los sujetos procesales interesados y rechazadas por el fiscal;

- audiencia de control del plazo de conclusión de la investigación preparatoria, luego de su formalización (343); 
- control en audiencia del requerimiento fiscal de sobreseimiento (346); y

- control en audiencia preliminar de la acusación fiscal (352).

Además del resguardo de garantías, a este juez le toca jugar un papel muy activo en el campo de la simplificación procesal o de la descarga de despachos, que haga manejable el número de causas que se ventilan cotidianamente. Por ello, luego de emitida la disposición fiscal de formalización de la investigación preparatoria (336), queda facultado para aplicar el principio de oportunidad y los acuerdos reparatorios (2), para acoger el requerimiento fiscal de un procedimiento abreviado o inmediato (446), que hace innecesaria gran parte de la investigación formal y la fase intermedia, y para aprobar el acuerdo de terminación anticipada al que arriban el fiscal y el imputado, y finalmente para emitir la sentencia condenatoria que recoja el consenso (468).

Aunque la regla del CPP es que la verdadera prueba se actúa durante juicio y no durante las etapas precedentes, como se ha dejado ver más arriba, existen circunstancias, por lo general sustentadas en razones de urgencia, para anticiparla, actuación que ha de llevarse adelante mediante audiencia conducida por el juez de la investigación preparatoria durante esta fase o en el curso de la intermedia.

\section{I.4. El juzgado penal y el juzgamiento}

La estructura o vía procesal emblemática del CPP es el proceso común (Libro Tercero), compuesto por tres etapas: la investigación preparatoria, la etapa intermedia y el juzgamiento. Si bien entre estas tres fases existe perfecta sincronía, no todas cuentan con igual peso o significado. Por esto, el canon ritual establece que «El juicio es la etapa principal del proceso» (356); es decir, las otras se encuentran claramente a su servicio. No podría ser otro modo. Mientras la investigación preparatoria busca que el fiscal reúna los elementos de convicción que le permitan decidir si formula o no acusación y a la defensa prepararse (321), y la etapa intermedia persigue confirmar o no la procedencia del sobreseimiento (344) o, en su caso, que la acusación tenga base suficiente para ser ventilada y discutida en la siguiente etapa, el juzgamiento ofrece el escenario donde la oralidad y la publicidad plenas harán posible que las pretensiones procesales adversas compitan, litiguen y que, sobre la base de la actuación de los medios de prueba (375-385), el tercero imparcial, es decir, el órgano jurisdiccional, valorando el resultado probatorio alcanzado, pronuncie sentencia absolutoria o condenatoria (398-399).

El CPP le confiere la conducción de tan trascendente etapa al Juzgado Penal, organismo que no ha intervenido en las fases anteriores para, de esta manera, acendrar su imparcialidad y dejar que sean los adversarios quienes, mediante la prueba, le lleven información de calidad y busquen alcanzar su convicción en un legítimo juego dialéctico, contradictorio,

LOS SUJETOS PROCESALES EN EL CÓDIGO PROCESAL PERUANO DE 2004 
abonado por la igualdad de armas entre acusación y defensa (I.3). Este Juzgado Penal puede ser unipersonal o colegiado, lo cual depende de la entidad de la causa que les competa. Así, los Juzgados Penales Colegiados (28) conocerán materialmente solo de los delitos que tengan señalados en la ley, en su extremo mínimo, una pena privativa de libertad mayor de seis años, y se reservarán los demás asuntos para los órganos unipersonales.

Por lo dicho, no cabe duda de que el éxito del juzgamiento dependerá de la acertada conducción que de esta fase haga el Juzgado Penal, pues habrá de tomar todos los cuidados para que, durante el período inicial, se produzcan los alegatos preliminares o de apertura de la acusación y la defensa; informará sobre sus derechos al acusado, entre ellos el de la libertad de manifestarse sobre la imputación o de no declarar (371); le preguntará si admite ser responsable del delito y la reparación civil; y dará pie, en caso de admisión, a la conclusión anticipada del juicio por conformidad (372). De lo contrario, se abrirá, para las partes o adversarios, la posibilidad de ofrecer nueva prueba y discutir sobre su admisión. Cumplido esto, se iniciará la actuación probatoria con el examen del acusado, si acepta deponer. Luego seguirán los testimonios y el examen de peritos, la introducción de la prueba material, la oralización de documentos y, cuando resulte indispensable, la inspección judicial y la reconstrucción de los hechos (375-385).

Durante la declaración del acusado (si ocurre) y los exámenes de testigos y peritos, el juez moderará el interrogatorio y decidirá, paso a paso, las objeciones que se formulen a preguntas capciosas, sugestivas o impertinentes (3784), que siempre desnaturalizan la limpieza de los interrogatorios y de los contra interrogatorios, y que demuestran una indebida técnica de litigación oral. Terminada la actuación de pruebas, el juez escuchará atentamente los alegatos finales, de cierre o clausura de las partes (386), así como la autodefensa del acusado (391), y procederá luego a deliberar según las reglas de la sana crítica, conforme a los principios de la lógica, las máximas de la experiencia y los conocimientos científicos $(393,158)$, y cuidará de excluir del acervo probatorio la prueba ilícita obtenida con violación de los derechos fundamentales (VIII, 159).

El producto de la deliberación judicial ha de ser la sentencia que impartirá justicia en el caso concreto. Esta destacará entre sus componentes la motivación clara, lógica y completa de cada uno de los hechos y de las circunstancias que se toman por probados o no, así como la valoración de la prueba que la sostiene, e indicará el razonamiento que la justifique (394).

Sobre la lectura de la sentencia el CPP trae una novedad que seguramente servirá para reconciliar al pueblo con sus magistrados: se trata de aquellos casos en los cuales, por la complejidad del asunto o lo avanzado de la hora, convenga diferir la redacción de la sentencia. 
Se leerá entonces solo la parte dispositiva, mientras que el juez o uno de los miembros del colegiado relatará sintéticamente al público los fundamentos que motivaron la decisión. Aquí, con este contacto oral del juez con el pueblo, surge la figura del magistrado docente o maestro, interesado en mejor las costumbres cívicas de sus conciudadanos (3962).

\section{I.5. La imparcialidad judicial: inhibición y recusación}

Porque las partes son parciales, el juez debe ser imparcial (I). Este axioma procesal rige el nuevo modelo que, como ya se tiene dicho, intenta no contaminar al Juzgado Penal con actividades precedentes al juicio. Ocurre, sin embargo, que la imparcialidad judicial no es necesaria solo en la oportunidad del juzgamiento, sino desde mucho antes, desde los primeros momentos de la investigación preparatoria y también en la etapa intermedia, porque en esas fases el juez de garantías interviene para tutelar al justiciable o restringir sus derechos fundamentales ante los requerimientos, por ejemplo, del Ministerio Público, y para ejercer control sobre el pedido de sobreseimiento o la acusación.

Desde esta óptica, cuando existan razones objetivas que pongan en entredicho su imparcialidad, es deber del juez inhibirse de seguir conociendo el caso (53). La gran mayoría de esas causales son explícitas, como el interés del juez en el proceso, su condición de acreedor o deudor del imputado, la víctima o el tercero civil, etcétera, y una de ellas es abierta: «cualquier otra causa, fundada en motivos graves [...]. Si pese a la concurrencia de alguno de los supuestos de inhibición previstos por la Ley, el Juez no se inhibe, las partes podrán recusarlo, dentro de los tres días de conocida la causal que invoquen (54), mientras la incidencia no esté resuelta el Juez cuestionado podrá resolver sobre la libertad o privación de ésta del imputado, así como practicar diligencias urgentes e irrealizables ulteriormente o improrrogables» $(56,52)$.

Entre persecución penal y defensa siempre habrá un conflicto. La regla estipula que el Ministerio Público tiene, entre sus obligaciones, que agrupar objetivamente elementos de convicción que le permitan acusar y probar luego lo acusado, en tanto que establece, a su vez, que la defensa tiene derecho a resistirse y desvirtuar la imputación. He aquí, desnuda, la esencia del litigio que sostienen estos actores del proceso, el que resultaría interminable e injusto si un tercero neutral no se ocupa del respeto al debido proceso y de todas sus garantías, como del pronunciamiento de una sentencia que con justicia y razón condene o absuelva. A nadie debe extrañar, en consecuencia, que cuando se inicia el juzgamiento el juez deba carecer de perjuicios o de ideas preconcebidas, tenga bien abiertos los oídos y los ojos para ser espectador de la actuación probatoria de las partes y recoger su resultado al valorarla. 


\section{II.LA DIVISIÓN DE FUNCIONES PROCESALES}

COMO CARACTERÍSTICA RESALTANTE DEL CPP El programa procesal penal de la Constitución desde 1979 estableció las vigas maestras sobre las cuales debía edificarse el nuevo proceso penal o el mecanismo de resolución de conflictos generados por el delito. Transcurridas muchas décadas y varios intentos de reforma, recién con el decreto legislativo 957 (CPP) de 29 de julio de 2004 se han desarrollado estas grandes pautas. Conforme con ellas, no existe proceso penal posible sin la concurrencia de sujetos procesales esenciales como el Ministerio Público, el imputado y su defensa, y el órgano jurisdiccional, encargados de específicas tareas: perseguir el delito, resistirse a la incriminación y fallar, respectivamente, sin admitir interferencias o postergaciones como las que caracterizan al modelo mixto de tendencia inquisitiva, donde el juez toma todas las riendas del caso y devalúa la intervención de los otros actores del proceso. Esta situación es la que finalmente nos ha conducido al estado de crisis e ineficacia crónica del servicio de justicia penal, generador permanente de descontento en la colectividad que se siente cada vez más insegura e intranquila, en los agraviados que no son resarcidos, menos indemnizados, y en los imputados que ven la escandalosa violación del plazo razonable ${ }^{4}$, circunstancia tanto más dramática cuando se trata de presos preventivos sin condena.

Ante semejante debacle, el CPP ha lanzado el reto, en el campo normativo, de una nueva estructura denominada proceso común (Libro Tercero), al que deben sujetarse las causas para alcanzar justicia pronta y cumplida. En el proceso común se ensamblan armoniosamente finalidades y tareas de diversa índole, bajo comando de su respectivo responsable. Así, la investigación preparatoria es entregada al Ministerio Público para que con toda amplitud decida el ejercicio de la acción penal y cumpla con la carga de la prueba, sin perder de vista que, durante esta fase, el juez ejerce tarea de tutela y al imputado se le reconocen derechos esenciales emanados de la presunción de inocencia (II, IX). En la etapa intermedia, gracias a las audiencias de control, se asegura la regularidad del sobreseimiento de lo actuado o el pase de la acusación a la etapa de juzgamiento, mediante la emisión del respectivo auto, cuando no la emisión de sobreseimiento por petición de parte o de oficio al carecer el dictamen fiscal acusatorio de suficiente peso para ingresar al juicio público y oral. En el juzgamiento, lo medular es la actuación probatoria que sostienen las partes ante el tercero imparcial para alcanzar su convicción y lograr que confirme su teoría sobre el caso mediante una condena o absolución.

Según se ve, en cada etapa del proceso común los actores cumplen la tarea asignada sin interferencias o invasiones funcionales, porque cada

4 Véanse las sentencias del TC sobre plazo razonable del proceso judicial y de la investigación fiscal: expedientes 3509-2009-PHC/TC. Lima, 19 de octubre de 2009 (Chacón), y 06079-2008-PHC/TC. Lima, 06 de octubre de 2009 (Abanto). 
uno de ellos tiene su respectiva misión. Normativamente, no hay forma, por ejemplo, de que el juez sustituya al fiscal en la tarea de pesquisa, o que en el juicio la actuación probatoria de las partes sea totalmente reemplazada por la prueba judicial de oficio (385.2). En suma, sin división de funciones procesales, no tendría el menor sentido asignarle al CPP la característica de acusatorio, garantizador y de tendencia adversativa: no pasaría de ser un cuerpo normativo más enfrascado en revitalizar el añoso y fracasado modelo mixto de tendencia inquisitiva, cuya peor expresión es el procedimiento sumario, enemigo jurado de la publicidad y de la transparencia.

\section{EL MINISTERIO PÚBLICO}

Condenado al papel de simple opinante por el C. de PP., la Constitución de 1979 y el decreto legislativo 052, trazando un cambio radical lo convirtieron en el órgano civil autónomo encargado de la persecución del delito, de la indagación de los hechos criminales desde su inicio, de la conducción de la policía en este terreno, de la representación de la sociedad durante juicio y de la titularidad del ejercicio de la acción penal.

A partir de esta transformación, los fiscales se pusieron en contacto directo con las noticias criminales y las denuncias de parte, y dispusieron, por lo general, la actuación de diligencias urgentes, a cargo de su propio despacho o derivadas a la policía, en lo que se conoce como «fase de investigación preliminar», orientada a recoger los elementos de convicción que les permita ejercitar la acción y formalizar denuncias ante el órgano judicial competente. Es precisamente en este aspecto que la actividad pesquisidora del Ministerio Público se ve afectada porque, no obstante tener vínculo estrecho con la indagación del acontecimiento delictuoso, debe, luego, derivar sus actuaciones al juez para que este las califique y decida si abre o no instrucción y proceda con una investigación formal que, en la mayoría de casos, no hace más que repetir lo realizado preliminarmente.

El CPP rompe este esquema y entrega la dirección de toda la etapa de investigación al fiscal, sin admitir interferencias judiciales en la indagación del delito; de ahí que considere al Ministerio Público como titular del ejercicio público de la acción penal, responsable de la carga de prueba y de la investigación criminal desde su inicio (IV).

\section{III.1. La importancia del «fiscal instructor»}

Entre las razones más importantes para que el CPP asigne la dirección de la investigación preparatoria al fiscal, contamos con aquella que indica que, en el marco de la distribución de funciones procesales del sistema acusatorio, está proscrito que quien investiga sea a la vez quien decida la causa, como ocurre en el procedimiento sumario. Desde ningún punto de vista es admisible que el persecutor, el actor enfrascado en 
indagar la existencia del delito y la responsabilidad, luego asuma la tarea de proceder imparcialmente, juzgar su propio trabajo y pronunciar sentencia. Hace bien el nuevo modelo, entonces, cuando desde el primer momento pone enfrente de la indagación al fiscal, aun cuando se trate de la práctica de diligencias preliminares o actuaciones de investigación urgentes e inaplazables (330.2). De este modo asegura la unidad de la pesquisa, que en ningún momento debe perderse, más aún si luego se emite la disposición fiscal de formalización y continuación de la investigación preparatoria (336), cuyo tránsito ulterior es lo que permite al fiscal decidir si con los elementos acopiados está o no en condiciones de formular acusación y pasar a la siguiente etapa del proceso común: la intermedia.

La clave se encuentra, entonces, en la unidad de la investigación bajo un solo mando, el del fiscal, razón más que suficiente para admitir que las diligencias preliminares son parte de la investigación y que, cuando esta se formaliza, ellas no pueden repetirse, salvo excepciones muy exigentes (337.2), entiéndase rehacimiento por grave defecto o ineludible complementación.

Razones de eficacia respaldan también la existencia de un fiscal estrictamente abocado a la investigación, pues es en estas circunstancias que puede poner en juego todos los mecanismos simplificadores que el CPP prevé para superar la sobre carga procesal. Es el caso de la facultad que se le reconoce para abstenerse de ejercitar la acción penal cuando se presentan criterios de oportunidad (2.1), el deber de promover la conciliación entre ofensor y ofendido al proponer acuerdos reparatorios (2.6), el planteamiento de una acusación directa (336.4), el requerimiento de incoación de un proceso inmediato (446) o la petición de una audiencia de terminación anticipada (468).

Ahora que se ha instituido plenamente la figura del «fiscal instructor», que se le ha conferido un escenario propio para sus actividades (la investigación preparatoria) y que se le ha liberado de cualquier interferencia en la pesquisa, no existe razón alguna para que la instrucción incumpla el plazo razonable o se adocene en el trabajo rutinario, carente de plan o de estrategia.

\section{III.2. Ocaso del juez instructor: razones para asignar al fiscal la dirección de la investigación}

Con el CPP desaparecen varios institutos procesales que no han ahondado la crisis del servicio. Se suprime la figura del juez instructor, quien, completamente alejado de la noticia criminal y de los actos de investigación preliminar, decide abrir o no instrucción y resuelve la situación procesal del imputado sobre la base de papeles o actas, sin escuchar al interesado y tampoco a su patrocinador; desaparece el secretismo informal que obstruye a la defensa bajo la consigna que «solo después de 
rendir instructiva podrá accederse a los actuados o al expediente» e igualmente se liquida la cultura de innecesaria repetición de las actuaciones efectuadas en sede fiscal o policial. Por esto, no perdemos nada diciéndole adiós al juez instructor, a quien el procedimiento sumario le ha adicionado la tarea incomprensible de sentenciar. En cambio, avanzamos mucho confiriendo la dirección de la indagación al fiscal: así aseguramos su cercanía a las noticias criminales y denuncias de parte, y, en su caso, su presencia en la escena del crimen, esto es, a las fuentes de prueba, evidencias, vestigios, instrumentos, objetos y efectos del delito $(326,329,330)$.

Toda esta información no puede quedar dispersa si no concentrarse en manos de un sujeto procesal como el fiscal para que elabore la estrategia de investigación adecuada al caso. La época del trabajo sin norte, rutinario y burocrático ha pasado. Hoy el CPP reclama un fiscal estratega que, desde el primer instante, programe y coordine con quienes corresponda el empleo de pautas, técnicas y medios indispensables para la eficacia de la investigación (65.4) y la progresiva construcción de su pretensión punitiva o teoría del caso.

Desde el ángulo garantizador es conveniente que el fiscal dirija la investigación porque, al no ser el abogado defensor de la víctima, sino de la sociedad, sus actuaciones se rigen por el principio de objetividad, lo que significa que durante la pesquisa ha de indagar tanto los hechos que acreditan la responsabilidad como los que abonan a la inocencia del imputado (IV.2) y ha de inquirir no solo las circunstancias que permitan comprobar la imputación, sino también las que sirvan para eximir o atenuar la responsabilidad del procesado (61.2). En suma, reunirá los elementos de convicción de cargo y de descargo (321).

Luego de mucho tiempo, finalmente, se deja el camino libre para que el fiscal cumpla con su trabajo a cabalidad y realice actos de pesquisa, carentes de carácter jurisdiccional (IV.3), que le sirvan a sus exclusivos propósitos de imputación, afirmación esta que nos permite, a su vez, diferenciar los actos de investigación enfilados únicamente a edificar una pretensión punitiva de los actos de prueba, capaces de soportar y fundar una sentencia, los primeros actuados durante la investigación preparatoria y los otros en el curso del juzgamiento.

\section{III.3. Relaciones entre el Ministerio Público y el juez de garantías}

El hecho de que la etapa de investigación preparatoria haya sido entregada, en su dirección y organización, al Ministerio Público no significa que se omitan contrapesos y balances dirigidos a asegurar su regularidad y su conformidad con el debido proceso. Por esta razón el CPP atribuye al juez que interviene en esta etapa funciones de tutela, garantía y control, de manera que cuando el fiscal necesita de una decisión

LOS SUJETOS PROCESALES EN EL CÓDIGO PROCESAL PERUANO DE 2004 
jurisdiccional la requerirá del órgano judicial y motivará debidamente su petición (IV.3). Esta relación fiscal-juez se aprecia claramente en el área de las medidas de coerción, especialmente las personales, como la detención preliminar en casos graves, no flagrantes (261) y la prisión preventiva (268), ninguna de las cuales será concedida al Ministerio Público sin expreso mandato judicial.

Otro terreno en el que el órgano jurisdiccional puede ejercer sus potestades de tutela y garantías es el referido a asuntos en que los derechos fundamentales del imputado son desconocidos por el Ministerio Público, o la policía, mediante una audiencia judicial de tutela de la que pueden derivar medidas de corrección o de protección (71.4).

Ahora que el nuevo modelo ya no admite la concurrencia de dos órganos investigadores (el fiscal por un lado y el juez instructor por el otro), envueltos ambos en demoras rutinarias y burocráticas, se libera de ataduras al juez para que, de manera eficaz, controle el estricto cumplimiento del plazo razonable, como se aprecia cuando, concluida la investigación, esta situación se posterga por inacción fiscal y se da pie a una audiencia de control de plazo para que el Ministerio Público se pronuncie requiriendo el sobreseimiento o acusando (343).

Durante la etapa intermedia, el fiscal pierde la dirección del proceso y la asume a plenitud el juez de la investigación preparatoria con dos propósitos, según sea el caso:

- controlar la regularidad del pedido de sobreseimiento fiscal, lo que importa que en audiencia se establezca que efectivamente se han configurado las causales del mismo, fácticas o técnico jurídicas (344); y

- controlar la acusación para determinar si tiene base suficiente y pasa a la etapa del juzgamiento (352), mediante la emisión del auto de enjuiciamiento (353).

El CPP ha redefinido, entonces, las relaciones entre el fiscal y el juez. Ya no se trata de socios comprometidos en la misma tarea de pesquisa, aquejados por idénticas deficiencias (rutina, burocracia, secretismo), sino de sujetos procesales con roles muy bien diferenciados: uno de actuación y operatividad indagatorias, el otro de garantías y control.

\section{III.4. El ejercicio de la acción penal y la titularidad de la carga de la prueba}

En el modelo acusatorio, el Ministerio Público reserva para sí, o monopoliza, el ejercicio de la acción penal para con los delitos de persecución oficial (IV.1, 11). Resulta lógico, entonces, que conduzca la investigación desde su inicio para obtener los elementos de convicción que acrediten los hechos punibles y las responsabilidades de sus autores o partícipes (65.1). 
Una vez que el fiscal recibe la noticia criminal o la denuncia de un acto ilícito, si el hecho reviste carácter delictuoso, tendrá que decidir el inicio de la investigación y dispondrá, por lo general, la realización de diligencias preliminares o pesquisas urgentes e inaplazables, e incluso podrá constituirse en el escenario del crimen para efectuar las comprobaciones ineludibles $(329,330)$.

Tratándose del ejercicio de la acción penal, el fiscal cuenta con varias alternativas:

- declarar que no procede formalizar ni continuar la investigación porque el hecho no constituye delito, no es justiciable penalmente o concurre una causa de extinción de la acción;

- ordenar la intervención policial para identificar al autor o partícipe del hecho delictuoso;

- reservar provisionalmente lo actuado por omisión de una condición de procedibilidad (334); y

- siempre que existan indicios reveladores de la existencia de un delito, emitir la disposición de formalización y continuación de la investigación preparatoria, lo cual afirma que la acción no ha prescrito, que se ha individualizado al imputado y que, en su caso, se han satisfecho los requisitos de procedibilidad (336).

Esto último importa el ejercicio público de la acción penal y acarrea dos importantes consecuencias: suspende la prescripción de aquella y elimina la facultad del fiscal de archivar la causa sin intervención judicial (339), lo que no ocurre si antes de emitir esta disposición de formalización se abstiene de ejercitar la acción en razón del principio de oportunidad o de un acuerdo reparatorio (2).

Otra manifestación del tema que nos ocupa está representada por el pronunciamiento acusatorio del fiscal durante la etapa intermedia (349): al emitir acusación no solo configura su pretensión procesal punitiva (pedido específico de imposición de pena para el acusado), sino que además ofrece los medios de prueba que actuará en juicio para probar su imputación.

Si el fiscal es el órgano de persecución, si dirige sin interferencias la pesquisa, si planifica el acopio de elementos de convicción sobre el hecho punible y sus responsables, resulta obvio que es a él a quien le corresponde probar, asumir la carga de la prueba (IV.1, 155.2) y desvirtuar la presunción de inocencia que favorece a todo imputado (II). Nadie que soporte una incriminación está obligado a declarar sobre los cargos (71), menos a confesar o admitir responsabilidad (160). Para el Estado constitucional, cuando de encontrar culpable a alguien y de condenarlo se trata, es indispensable que la presunción de inocencia del encausado sea desvirtuada a plenitud, más allá de cualquier duda razonable. Con tal objetivo se ha edificado un órgano civil autónomo de investigación,

LOS SUJETOS PROCESALES EN EL CÓDIGO PROCESAL PERUANO DE 2004 
el Ministerio Público, quien para efectuar su trabajo además cuenta con la invalorable contribución de la policía (IV.2, 60.2, 67.2, 331) y con la colaboración de toda autoridad y funcionario público (322.2).

Conviene tener en cuenta que la carga de la prueba no puede ser atendida a cualquier costo por el fiscal, pues encuentra su límite o valladar infranqueable en el respeto de los derechos fundamentales de la persona. Cuando esto es infringido, surge la prueba ilícita o prohibida y se impone la regla de exclusión probatoria que invalida todo medio de prueba ilegalmente obtenido (VIII, 155.1).

\section{III.5. La dirección jurídico-funcional-fiscal de la labor policial}

El Ministerio Público es el único organismo que puede ocurrir ante el Poder Judicial para reclamar que se declare culpable y se sancione a un procesado. Cuando se trata de delitos de persecución oficial o pública, ninguna otra entidad, por más encumbrada que sea, puede desconocer esta vía, ello por la sencilla razón de que todo proceso penal, para ser debido, necesita recorrer una etapa inicial o preparatoria (la investigación) de cuyo resultado dependerá el planteamiento o no de una acusación.

La Constitución de 1979, felizmente repetida en este punto por la vigente de 1993 (159.4), al diseñar el proceso penal democrático dispuso que el Ministerio Público se encargue de conducir desde su inicio la investigación del delito, a la vez que determinó un cierto tipo de relaciones entre las fiscalías y la policía, e indicó que con este propósito esta última está obligada a cumplir los mandatos del Ministerio Público en el ámbito de su función.

Desde la perspectiva constitucional no existe base alguna, entonces, para equiparar los roles de un organismo con el del otro. Es cierto que la pesquisa del delito requiere, casi siempre, la actuación del binomio fiscal-policía, pero de ahí no se puede concluir que la estrategia y el planeamiento de la investigación le competan tanto a la policía como al fis$\mathrm{cal}$, o que existen dos conductores o direcciones. El CPP es terminante. La estrategia es prerrogativa fiscal y de nadie más. El Ministerio Público ordena, cuando corresponde, la intervención policial (65). La policía da cuenta inmediata a la fiscalía de las noticias criminales $(60,331.1)$, adelanta ciertos actos de investigación urgentes e imprescindibles (67) y formula un informe objetivo que recoja, ante todo, las intervenciones practicadas, y se abstiene de calificar jurídicamente los hechos y de imputar responsabilidades (332).

Nada de lo dicho se contradice con la previsión del Código en el sentido de que el Ministerio Público conduce y controla jurídicamente los actos de investigación que realiza la policía (IV2) porque con ello se cubre la misión fiscal dirigente de las actuaciones operativas de la fuerza pública, así como la legalidad o la regularidad jurídica de ellas, con el interés de 
que toda intervención policial esté rodeada de legitimidad y escrupuloso respeto de la ley. Tal el caso de los cuidados que deben tomarse cuando se procede a detener a una persona $(259,263)$, cuando se registra la escena del crimen o cuando se elabora la cadena de custodia de la evidencia $(220.5,318.1)$.

\section{III.6. El rol del fiscal en el juzgamiento}

Al ser el juicio público y oral la etapa principal del proceso común (356), habrá que reconocerlo también como el escenario natural de la contraposición de las teorías del caso o pretensiones procesales que traen las partes ante el tercero imparcial u órgano jurisdiccional. Nos referimos a las afirmaciones o a los relatos que ofrecen probar el Ministerio Público y la defensa del acusado, las primeras como expresión de lo punitivo y los segundos de lo libertario. En este terreno, la actividad probatoria descansa esencialmente sobre los hombros de los adversarios en litigio, quienes deberán esforzarse por llevarle al juez información de calidad y por convencerlo para que, valorando la prueba actuada, recaben de él una sentencia de condena o de absolución.

Bien apreciadas las cosas y vigente la presunción de inocencia, no resulta equivocado indicar que la tarea más esforzada en el juzgamiento le compete al fiscal. Es quien trae una teoría del caso completa, integral, o una pretensión que debe intentar demostrar fehacientemente, ya que, por el lado del imputado y de su defensor, la actitud puede ser simplemente pasiva o reactiva. Mientras la insuficiencia de pruebas o la duda acarrean absolución, solo la suficiente actividad probatoria de cargo obtenida y actuada con las debidas garantías procesales es idónea para sostener una condena (II.1). Y es a esta tarea tan compleja y exigente a la que debe abocarse, con denuedo, el fiscal, con cuidado de llevar eficazmente a la práctica su plan de formulación de alegatos de apertura, interrogatorio de acusado, testigos y peritos, de empleo de la prueba material, de oralización de instrumentos y de alegación de clausura o de cierre.

\section{III.7. El principio acusatorio y la separación de las funciones judicial y fiscal (jurisdicción y acusación)}

Según este principio, que a la vez constituye uno de los pilares de la reforma, las funciones de la persecución han de estar claramente separadas de la tarea de impartir o administrar justicia. En el litigio penal no es admisible que la parte que investiga y, en su caso, solicita la declaración de culpabilidad e imposición de pena sea la misma que luego decida el conflicto. El proceso está estructurado de tal manera que el acusador actúa toda la prueba de cargo que respalda su imputación para que, gracias a la inmediación o al contacto del juez imparcial con la prueba, así como al contradictorio, o contraposición o rechazo de la defensa de los cargos, el órgano jurisdiccional valore su resultado y emita sentencia. El juez, en consecuencia, no puede ingresar al juzgamiento prejuiciado o con

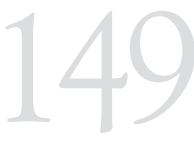

LOS SUJETOS PROCESALES EN EL CÓDIGO PROCESAL PERUANO DE 2004 
ideas preconcebidas sobre el asunto: tiene que hacerlo completamente libre de cualquier influencia interna o externa que le impida escuchar debidamente a la acusación y a la defensa. Desde este punto de vista, el CPP atribuye la actuación probatoria a las partes $(155.2)$ y muy excepcionalmente permite la prueba de oficio (155.3 y 385), con cuidado de no reemplazar por este medio la actuación de los adversarios en la litis.

Gracias a que el juez dirige el juicio sin compromisos antelados con el Ministerio Público o la defensa, y a que su tarea es muy diferente de la de estos otros sujetos procesales, puede asegurar con firmeza la vigencia de los principios que rigen esta fase: oralidad, publicidad, inmediación, contradicción en la actuación probatoria, continuidad, concentración, identidad física del juzgador y presencia obligatoria del imputado y de su patrocinador (356).

\section{III.8. Postulación de parte y pretensión punitiva}

Durante la etapa intermedia, el Ministerio Público configura su pretensión punitiva y la explicita en su acusación escrita (349), sujeta a los controles de la audiencia preliminar (351), de cuyo resultado dependerá si pasa o no a la etapa de juzgamiento. A partir de este momento la fiscalía adquiere la condición de parte, en igualdad de condiciones o armas que la defensa, puesto que ambos sectores postularán en el juicio los relatos que pretenden acreditar ante el juez imparcial. Por esto se les reclama, al iniciarse el juicio, que efectúen sus alegatos de entrada, preliminares o de apertura (371.2), para que quede establecido cuál es el caso y los puntos que se van a debatir y los medios de pruebas admitidos que se van a practicar. Como se ve, la igualdad de armas es una exigencia derivada de la postulación de parte que evita privilegiar la acción institucional del Ministerio Público y menoscabar o dificultar la labor privada de la defensa. El juicio es dirigido por el Juzgado Penal sin haberse contaminado o prevenido por las actuaciones realizadas en las etapas anteriores del proceso, lo que le permite dirigir eficazmente el debate de las partes y dedicarse a valorar la actuación probatoria para luego de deliberar expedir sentencia.

\section{III.9. El principio de objetividad y la labor del Ministerio Público}

Se ha dicho que el fiscal no es el abogado de la víctima o del agraviado, sino de la sociedad. Ello quiere decir que al Ministerio Público le interesa sobre manera el esclarecimiento material y la reconstrucción de los hechos, y no siempre una persecución a cualquier costo. La sociedad no solo se intranquiliza cuando el delito queda impune o no es elucidado, sino también cuando las incriminaciones son equívocas o abusivas. Sobre esta base descansa el principio de objetividad de la labor fiscal y así lo entiende el CPP, que tempranamente la hace responsable de indagar los hechos que determinen o acrediten tanto la responsabilidad como la 
inocencia del imputado (IV.2) o le exige que pesquise las circunstancias que permitan comprobar la imputación y también las que sirvan para eximir o atenuar la responsabilidad del imputado (61.2).

Lo mismo puede decirse de la alternativa que el fiscal posee para, una vez concluida la investigación preparatoria, requerir el sobreseimiento del caso (344.2) o acusar (349), dependiendo de la mayor o de la menor envergadura de los elementos de convicción que haya reunido durante la investigación.

Hallamos manifestaciones del principio de objetividad que rige la actuación fiscal en su prerrogativa de retirar la acusación en juicio cuando considera que los cargos formulados han sido enervados (387.4), así como en la facultad de impugnar o de recurrir en favor del imputado (405.1.a).

\section{EL IMPUTADO Y SU ABOGADO DEFENSOR}

Sin defensa no hay proceso. Este axioma jamás debe ser olvidado, pues engarza perfectamente con el principio de presunción de inocencia (II) y el derecho de resistencia ante la persecución penal (IX). A la Constitución y al CPP les importa que al imputado o a la persona que soporta una incriminación, desde que se adelanta contra él siquiera una sospecha de intervención en un evento criminal, se lo reconozca como sujeto procesal rodeado de garantías y escudos protectores, y no como un simple objeto de indagación, infeliz papel al que lo ha reducido, hasta hoy, el procedimiento mixto de tendencia inquisitorial.

\section{IV.1. El derecho de defensa: derechos del imputado}

Uno de los aspectos más útiles del derecho de defensa que asiste al imputado es el de la información. Para el CPP han pasado al desván de la historia los estilos de trabajo y las técnicas sustentados en el secretismo o en la reserva a ultranza de la investigación. Hoy el modelo garantizador exige que el incriminado sea informado sobre sus derechos y comunicados de inmediato y detalladamente los cargos que se le hace (IX.1). Pero la información no es el único derecho inviolable del citado o detenido por la autoridad, sino que este va aparejado por la obligación de ella de hacerle comprender los siguientes derechos:

- a conocer los cargos en su contra o los motivos de su detención, incluida la orden que la contiene;

- a designar persona o institución que deba ser avisada inmediatamente de su detención;

- a ser asistido en todo momento por un abogado defensor;

- a guardar silencio o no declarar;

- a no autoinculparse o responsabilizar a sus familiares;

LOS SUJETOS PROCESALES EN EL CÓDIGO PROCESAL PERUANO DE 2004 
- a que no se empleen en su contra coacción, intimidación, tratos humillantes ni técnicas que induzcan o alteren su libre voluntad;

- a no sufrir restricciones ilegales; $y$

- a ser examinado por un médico cuando su estado de salud lo requiera $(71)$.

Cuando estas exigencias no son cumplidas, el CPP ha previsto un mecanismo de solución constituido por la audiencia de tutela (71.4) de la que pueden derivarse medidas judiciales de corrección o de protección que atajen los abusos cometidos contra el imputado.

Considerando que su declaración es un derecho y no una obligación, esta se rodea del cumplimiento de instrucciones previas (como la comunicación detallada del hecho atribuido, los elementos de convicción y pruebas existentes), de la advertencia de que está facultado a no declarar, de que dicha decisión no se empleará en su perjuicio y de que tiene derecho a la presencia de un defensor de elección o de oficio (87).

Otras muestras de respeto por el derecho de defensa que encontramos en el CPP tienen que ver con la oportunidad que se brinda al procesado para que en las audiencias intervenga en último término (8) o efectúe en juicio su autodefensa material (391). En la oportunidad de su apertura, esta etapa presenta al juez informando al acusado de sus derechos e indicándole que es libre de manifestarse sobre la acusación o de no declarar sobre los hechos (3713).

Solo cuando se hayan respetado pulcramente la totalidad de los derechos del imputado y su dicho haya sido recibido libremente y en estado normal de sus facultades psíquicas, ante el juez o el fiscal y en presencia de su abogado, además de la respectiva corroboración de lo declarado, lo que manifieste tendrá calidad de confesión válida (160).

\section{IV.2. Defensa técnica obligatoria e irrenunciable}

Ser informado y oído no es suficiente para que el buen servicio de la defensa del imputado opere a plenitud. Dado que el proceso penal es un mecanismo técnico, edificado y regido por normas jurídicas, sujetas a interpretación, el incriminado requiere tener junto a sí un profesional del derecho que, conjuntamente con él, enfrente la delicada tarea de oponerse a la persecución fiscal.

La defensa técnica, es decir la del patrocinador, es obligatoria e irrenunciable porque es la única capaz de elaborar una teoría del caso desde la perspectiva libertaria, de intervenir en las actuaciones de investigación, de proponer las de descargo, de generar o participar en los incidentes, de ofrecer y conseguir la admisión de medios de prueba, de alegar y debatir en las audiencias, de formular alegatos y de incursionar en la actuación y en el debate probatorio, premunido de las técnicas de litigación más 
convenientes. Sin el concurso de un abogado defensor, el imputado no tendría cómo canalizar su protesta de inocencia o de irresponsabilidad, o cómo aprovechar las salidas alternativas y simplificadoras que ofrece el código: quedaría, pues, atrapado en los engranajes de un sistema para él incomprensible.

\section{IV.3. Derechos del abogado defensor}

Entre los más significativos tenemos los siguientes:

- intervenir tempranamente en el patrocinio, desde que el imputado es citado o detenido;

- interrogar a su defendido y a coprocesados, testigos y peritos;

- asistirse por expertos durante el desarrollo de una diligencia técnica;

- participar en todas las diligencias del proceso;

- allegar medios de investigación y de prueba de descargo;

- presentar peticiones para asuntos de simple trámite;

- acceder al expediente fiscal y judicial;

- obtener copia simple de las actuaciones en cualquier estado del procedimiento;

- ingresar a los penales y locales policiales para entrevistarse con su patrocinado; expresar sus propuestas con amplia libertad;

- interponer medios de defensa e impugnar (80).

Mientras el C. de PP y el procedimiento sumario no han hecho más que entorpecer la actividad del abogado defensor, al ponerle toda clase de cortapisas y al considerarlo un sujeto procesal molesto o incómodo, el CPP, aplicando una política de transparencia y efectivizando del principio de igualdad, le confiere amplias atribuciones para que planifique su defensa. Le concede así un tiempo razonable con tal fin y, sobre todo, para que intervenga en la actividad probatoria y utilice los medios de prueba pertinentes (IX). Debidamente informado, gracias a la concesión de copias simples de lo actuado, dependerá del abogado defensor, de su arte para manejar las herramientas de la litigación oral, que la pretensión libertaria del imputado prospere y sea confirmada con una sentencia absolutoria. Pasado el momento de la ineficaz rutina, de la escritura, del culto al expediente y del secretismo, el defensor en el nuevo modelo tendrá que consolidar su trabajo sustentado en la oralidad, la publicidad y el régimen de audiencias. Este es el reto para cuyo afrontamiento el CPP concede facultades al abogado defensor, mediante lo cual privilegia su talento y su preparación, y desecha las distorsiones profesionales tan nocivas, como nexos o compadrazgos con magistrados, y las vertientes ilícitas del asunto: el cohecho. 


\section{IV.4. El defensor de oficio o público}

Fuera de los casos de criminalidad organizada y funcionarial, el perfil de nuestra realidad delictuosa está regido por la comisión de delitos de pobres contra pobres. Esta situación ofrece terreno fértil a la operatividad de la defensa de oficio para servir a los imputados que carecen de recursos para designar un abogado de elección, o cuando se presentan circunstancias que reclaman el concurso de un defensor de este tipo para garantizar la legalidad de una diligencia y el debido proceso (IX.1, 80).

Para el CPP, el defensor de oficio no es un sujeto procesal desdeñado o sometido a los designios de fiscales o jueces, un personaje al que se atesta con expedientes a último momento para salvar las formalidades del antiguo juzgamiento. Por el contrario, el nuevo modelo reclama una defensa de oficio o pública institucional, bien capacitada e implementada, cuya labor satisfaga idénticos o mejores estándares de eficacia que la defensa paga. Lo central del asunto reside en buscar que, ante un poderoso Ministerio Público apoyado por la policía, se erija, con equivalente perfil, un auténtico servicio de defensa pública o de oficio.

\section{VÍCTIMA Y ACTOR CIVIL}

El CPP ha rescatado a la víctima del olvido en que la tuvo el viejo sistema, la ha vigorizado al afirmar su derecho a la información y participación procesal (IX.3), se ha preocupado porque alcance efectivo resarcimiento e indemnización por los daños que el delito le ha infligido (11), la ha comprendido en el conjunto de sujetos procesales (94) y le ha extendido protección a través de medidas eficaces que fiscales o jueces adoptarán, como el cambio de residencia, la ocultación de su paradero o el uso de procedimientos tecnológicos (por ejemplo, las video conferencias) que conjuren el peligro para su seguridad $(247,248)$.

El agraviado, por el solo hecho de serlo, sin que para ello sea requisito previo constituirse en actor civil, tiene derecho a ser informado del resultado del proceso, a ser oído antes de que se adopten decisiones que importen la extinción o la suspensión de la acción penal, cuando lo solicite, y a impugnar el sobreseimiento y el fallo absolutorio (95). Entre las innovaciones que en este campo trae el nuevo modelo, tenemos:

- aun cuando se absuelva o sobresea, el órgano jurisdiccional se pronunciará sobre la acción civil derivada del hecho punible, siempre que ello resulte procedente;

- el perjudicado podrá ejercitar dicha acción en sede penal o en sede civil, pero una vez que haya optado por una de ellas no podrá deducirla en la otra vía;

- es procedente la nulidad de transferencias cuando el infractor, luego de la comisión del delito, se despatrimonializa o desposee de sus bienes $(15,11.2)$; y 
- las asociaciones u organizaciones sociales que, en delitos que afectan intereses colectivos, lesionen un indeterminado número de personas o constituyan crímenes internacionales, tendrán la posibilidad de ejercer los derechos y facultades asignadas a las personas directamente ofendidas (944), lo que en los delitos contra la humanidad implica reconocer a la víctima el derecho a la verdad $^{5}$, como ocurre en los trágicos casos de desapariciones forzadas que asolaron el país en el pasado conflicto armado interno.

Para alcanzar plena participación procesal en el ámbito incidental, de la actividad de investigación y de prueba e impugnar (104), el perjudicado deberá solicitar constituirse en actor civil y ser constituido como tal por el juez de la investigación preparatoria, hasta antes de la culminación de esta etapa $(100,101,29.1)$; así podrá colaborar con la elucidación de los hechos y de la intervención del imputado en estos, y probar la reparación civil que pretende (105). En esta última materia, el CPP ha tomado un nuevo camino al estipular que la legitimación del Ministerio Público para intervenir en el objeto civil del proceso cesa cuando el perjudicado se constituye en actor civil. No escapará al más simple razonamiento que con esto las fuerzas del órgano de persecución serán liberadas para enfocarse en lo que puntualmente les corresponde: investigar el delito, acusar cuando sea el caso y probar lo acusado en juicio, además de recabar del juez imparcial una sentencia condenatoria.

\section{CONCLUSIÓN}

En suma, para el nuevo ordenamiento procesal penal, edificado según el modelo acusatorio, garantizador y de tendencia adversativa, que hoy rige integralmente en varios distritos judiciales del país ${ }^{6}$, resulta nítido que sin persecución, defensa y fallo, entendidas como funciones diferenciadas y a cargo de su correspondiente sujeto procesal, no es posible predicar la existencia de un proceso justo, debido y legal, propio de un régimen democrático y republicano al servicio de los ciudadanos.

\section{INTERROGANTES Y CASOS PRÁCTICOS}

\section{VII.1. Sujetos procesales: juez y partes procesales (16-59, 60-113)}

A. Raimundo Sujetil Partenón afronta una investigación que, luego de las diligencias preliminares, se ha formalizado por el delito de tráfico ilícito de drogas, en modalidad agravada (297 CP).

5 Sentencia del Tribunal Constitucional del 18 de marzo de 2004, expediente 2488-2002-HC/TC (Caso Villegas). En <http://www.tc.gob.pe/jurisprudencia/2004/02488-2002-HC.html>.

6 Huaura, La Libertad, Arequipa, Tacna, Moquegua, Lambayeque, Piura, Tumbes, Cusco, Puno, Madre de Dios, Cañete, Ica, Cajamarca, San Martín y Amazonas.

LOS SUJETOS PROCESALES EN EL CÓDIGO PROCESAL PERUANO DE 2004 
1. ¿Qué juez tendría que haber intervenido si el fiscal, antes de la formalización, hubiese requerido la detención preliminar judicial de Raimundo?

2. ¿Por qué en el proceso contra Raimundo, hasta antes del juzgamiento, no interviene el Juzgado Penal Colegiado?

3. ¿Qué competencias ejercitaría la Sala Penal Superior en la causa contra Raimundo?

4. ¿En qué supuestos intervendría la Sala Penal Suprema en el asunto de Raimundo?

B. La ciudadanía de Trujillo vive mortificada, intranquila e insegura por la proliferación de las extorsiones cometidas por bandas cuyos jefes residen en los penales de la ciudad.

1. ¿Qué actitud debe tomar el Ministerio Público ante este problema?

2. ¿Cómo ha de entenderse el proceder estratégico del Ministerio Público ante el delito?

3. Luego de formalizada y concluida la investigación contra los extorsionadores, ¿qué tareas asumirá el Ministerio Público?

4. ¿Cuál será la labor central del Ministerio Público en el juzgamiento que se realice contra los acusados por extorsión?

C. Eduardo Inculpo Encarton ha sido intervenido por la policía inmediatamente después de asaltar (189 CP) el banco de un poblado muy lejano. Quedó gravemente herido como consecuencia de la detención policial, pues disparó contra sus captores y motivó que estos respondieran. El comisario informa sobre todo lo sucedido al fiscal competente, quien no puede constituirse de inmediato al lugar de los hechos por lo intransitable de la carretera debido a las fuertes lluvias, propias de la estación.

1. ¿Podrá la policía adelantar diligencias de investigación sin orden fiscal?

2. ¿Será válida la declaración que la policía tome a Eduardo sin la presencia del fiscal?

3. ¿Cómo se concretará la dirección fiscal de la labor policial en este caso?

D. Manuel Indagón Miradas es investigado por violación sexual de menor de edad, en agravio de su nieto Luis, de 4 años (173 CP).

1. ¿Qué derechos, garantías y escudos protectores asisten a Manuel para afrontar esta grave incriminación?

2. ¿Basta la sospecha contra Manuel para habilitar su derecho a la defensa? 
3. ¿Cómo compatibiliza la presunción de inocencia, que beneficia a Manuel, con la investigación de los cargos que pesan en su contra?

E. Ximena Riqueña Solventa es la agraviada o víctima en un proceso seguido a Luis Uñasqui Larguín por hurto agravado por nocturnidad (189 CP). Tras el juicio, Luis es absuelto.

1. ¿Podrá Ximena apelar la sentencia absolutoria sin previamente haberse constituido en actora civil?

2. ¿Cómo el actor civil es constituido sujeto procesal y quiénes pueden ser considerados como tales?

3. ¿Tendría Ximena la posibilidad de impugnar, si a Luis se le hubiese sobreseído la causa, antes del juicio, al declararse fundada una excepción de improcedencia de acción?

F. Juan Aspiración Narigel y José Trafison Extranjes constituyen una persona jurídica (Buen Vuelo SAC) dedicada a la exportación de alimentos, cuya representación ejerce Nemesio Representato Asumil. Aprovechando la organización de esta empresa, Juan y José exportan cocaína a Italia, camuflada en barriles de cocona.

1. ¿Será comprendida en el proceso la empresa de Juan y José?

2. ¿Quién será citado a proceso para representar a la persona jurídica involucrada?

3. ¿Las decisiones judiciales que se adoptasen contra esta SAC revestirán naturaleza punitiva?

G. Pedro Sucial Contamin, aprovechando que trabaja en la tienda de Serapio Comercin Gananciol, vende productos corrompidos, que trae de su casa y mezcla con las mercancías de la tienda. Estos productos son potencialmente nocivos para la salud de las personas $(288 \mathrm{CP})$.

1. ¿Serapio será comprendido en el proceso penal seguido a Pedro?

2. ¿El hecho que se incluya en la causa a Serapio importa la posibilidad de punirlo?

H. Matías Amical Suficien sabe que Ricardo Uñasqui Malin enfrenta un proceso penal. Sin embargo, acepta comprarle el inmueble que este construyó varias décadas atrás por un precio algo mayor que el promedio del mercado.

1. ¿Debe comprenderse a Matías en el proceso de Ricardo?

2. ¿Qué determinaciones tomará el juez de la causa a propósito del negocio celebrado por Matías?

LOS SUJETOS PROCESALES EN EL CÓDIGO PROCESAL

PERUANO DE 2004 